\title{
Predictors of 1-Year Rehospitalization for Patients with Major Depressive Disorder: A Retrospective Study in a University Hospital
}

\author{
Ji-Min Yoo, MD, Sung-Min Kim, MD, Yoo-Hyun Um, MD, Tae-Won Kim, MD, Ho-Jun Seo, MD, \\ Seung-Chul Hong, MD, Jong-Hyun Jeong, MD \\ Department of Psychiatry, St. Vincent's Hospital, College of Medicine, The Catholic University of Korea, Suwon, Korea
}

\begin{abstract}
Background: This study aimed to assess the clinical characteristics of patients with major depressive disorder who were rehospitalized within 1 year and to determine whether the 1-year rehospitalization rate varied depending on the type of medication and treatment method.

Methods: Clinical characteristics of 531 patients hospitalized for major depressive disorder were assessed. The use and type of antidepressants, antipsychotics, mood stabilizers, and hypnotics were also evaluated.

Results: Of the 531 subjects, 68 (12.8\%) were rehospitalized within a year. The number of past depressive episodes $(1.56 \pm 2.67$ vs. $0.90 \pm 1.18)(p=0.048)$ and the number of previous psychiatric hospitalizations $(0.82 \pm 1.93$ vs. $0.29 \pm 0.83$ times) $(p=0.029)$ were high in the 1 -year rehospitalization group. The rate of family history of mood disorder $(25.0 \%$ vs. $13.6 \%)(p=0.014)$ and the rate of comorbid personality disorder $(16.2 \%$ vs. $8.6 \%)(p=0.049)$ were also high in the 1 -year rehospitalization group. Multiple logistic regression analysis showed that the number of previous psychiatric hospitalizations affected the rate of 1 -year rehospitalization $(p=0.003)$.

Conclusion: The number of previous psychiatric hospitalizations could be used to predict rehospitalizations of patients with major depressive disorder within 1 year. In addition, family history of mood disorders and comorbidity of personality disorders may affect rehospitalization of such patients.
\end{abstract}

Keywords Major depressive disorder; Patient readmission; Antidepressants

\section{INTRODUCTION}

Major depressive disorder is a common disease with a prevalence of $15 \%$ [1-3]. It burdens the affected individuals and largely increases the social cost [1-3]. Also, major depressive disorder has a high tendency for recurrence. At least $50 \%$ of those who experienced their first episode suffer recurrence of symptoms, and the recurrence rate of those who experience two episodes reaches up to $80 \%$ [4-6].

Most patients with major depressive disorder are treated by outpatient clinic, and only a small proportion requires hospitalization [7]. Rehospitalization implies recurrence of depression or hypofunction that is difficult to improve via outpatient clinic after discharge [8]. Also, the cost of hospitalization and rehospitalization is high [8]. Given that repeated hospitalization is likely to lead to collapse of support base and to social stigma $[9,10]$, it is important to assess the risk factors of rehospitalization due to depression as well as its recurrence.

In previous studies, the number of previous psychiatric hospitalizations and psychiatric hospitalization

Received June 4, 2021, Revised July 6, 2021, Accepted July 6, 2021

Correspondence: Jong-Hyun Jeong, MD

Department of Psychiatry, The Catholic University of Korea, St. Vincent's Hospital, 93 Jungbu-daero, Paldal-gu, Suwon 16247, Korea

TEL +82-31-249-7150 FAX +82-31-248-6758 E-mail anton3@catholic.ac.kr ORCID https://orcid.org/0000-0003-3570-7607

Copyright $\odot$ by Korean Society for Affective Disorders.

This is an Open Access article distributed under the terms of the Creative Commons Attribution Non-Commercial License (http://creativecommons.org/licenses/ by-nc/4.0/) which permits unrestricted non-commercial use, distribution, and reproduction in any medium, provided the original work is properly cited. 
within last 5 years, and comorbid diseases were known to be the risk factors for rehospitalization in patients with major depressive disorder $[8,11]$. Some studies have argued that comorbidity of alcohol abuse and personality disorders, old age, and low medication compliance are risk factors for rehospitalization [8,12-15]. In a previous study, the number of hospitalizations for previous psychiatric disease was related to rehospitalization [16]; however, there was limitation in assessing other factors related to rehospitalization due to small number of cases. The purpose of this study was to increase the number of cases to assess the 1-year rehospitalization rate of patients with major depressive disorder, and to compare the characteristics of rehospitalized patients with those who did not. In addition, we tried to evaluate whether the rehospitalization rate varies depending on the type of antidepressant and treatment method, and the time to rehospitalization.

\section{MATERIALS AND METHODS}

\section{Study population}

Patients admitted to the Department of Psychiatry at St. Vincent Hospital, The Catholic University of Korea from 1 January 2010 to 31 December 2017 for major depressive disorder diagnosed based on diagnostic criteria of Diagnostic and Statistical Manual of Mental Disorders, fourth edition (DSM-IV) [6] or fifth edition (DSM5) [17] were enrolled. Diagnosis was based on the final diagnosis confirmed at discharge. Standard hospitalization included only the first admission to the hospital during the above period for major depressive disorder according to the DSM diagnostic criteria and only the patients who were followed-up for one year from discharge date were included. This study was approved by the Institutional Review Board (IRB approval number: VC20RISI0270) at The Catholic University of Korea, St. Vincent Hospital. The informed consent was waived because this study was conducted using confidential medical records review assuring confidentiality.

\section{Evaluation}

Clinical variables including age at the time of hospitalization, sex, length of illness, length of hospitalization, years of education, socioeconomic status, marital status, severity, presence of psychotic symptoms, presence of anxious distress, number of past depressive episodes, number of past psychiatric hospitalizations, family history of mood disorders, comorbidity of substance use disorders, anxiety disorders, and personality disorders were assessed by reviewing medical records.

Use of antidepressants, antipsychotics, mood stabilizers, and hypnotics was assessed by reviewing the medical records and prescription records.

\section{Statistical analysis}

IBM SPSS Statistics for Windows, Version 24.0 (IBM Corp., Armonk, NY, USA) and PASW Statistics for Windows, Version 18.0 (SPSS Inc., Chicago, IL, USA) were used for analysis. A p-value $<0.05$ was considered statistically significant. Student t-test was used for analysis of age, length of illness, length of hospitalization, years of education, and number of past depressive episode and previous psychiatric hospitalizations. Chisquare test and Fisher's exact test were used for assessing severity, presence of psychotic symptoms, presence of anxious distress, family history of mood disorders, comorbidity of substance use disorders, anxiety disorders and personality disorders, types of antidepressants, treatment methods, and use of hypnotics.

Multiple logistic regression test was conducted based on the selected variables. The mean and median of time to rehospitalization for only the 1-year rehospitalization group was calculated and shown as Kaplan-Meier survival curve.

\section{RESULTS}

\section{Demographic characteristics}

A total of 531 patients were enrolled, of which 68 $(12.8 \%)$ were rehospitalized within 1 year (1-year rehospitalization group), and 463 (87.2\%) were not (control group). There were no statistically significant differences in age, sex, years of education, marital status, and socioeconomic status between the two groups (Table 1).

\section{Clinical characteristics}

Univariate analysis showed statistically significant difference in number of past depressive episode in the 
Table 1. Demographic characteristics of study participants $(n=531)$

\begin{tabular}{|c|c|c|c|}
\hline Variable & Rehospitalized patients $(n=68)$ & Non-rehospitalized patients $(n=463)$ & $p$-value \\
\hline Age (y) & $54.66 \pm 18.42$ & $55.44 \pm 18.36$ & NS \\
\hline Sex & & & NS \\
\hline Male & $22(32.4)$ & $118(25.5)$ & \\
\hline Female & $46(67.6)$ & $345(74.5)$ & \\
\hline Education (y) & $9.63 \pm 4.16$ & $9.09 \pm 4.85$ & NS \\
\hline Marital status & & & NS \\
\hline Single & $16(23.5)$ & $85(18.4)$ & \\
\hline Married & $37(54.4)$ & $244(52.7)$ & \\
\hline Separate/divorced & $4(5.9)$ & $66(14.3)$ & \\
\hline Bereaved & $11(16.2)$ & $68(14.7)$ & \\
\hline SES & & & NS \\
\hline High & $2(2.9)$ & $24(5.2)$ & \\
\hline Middle & $57(83.8)$ & $358(77.3)$ & \\
\hline Low & $9(13.2)$ & $81(17.5)$ & \\
\hline
\end{tabular}

Values are presented as mean \pm standard deviation or number (\%).

SES, Socioeconomic status; NS, not significant.

Table 2. Clinical characteristics of study participants $(n=531)$

\begin{tabular}{|c|c|c|c|}
\hline Variable & $\begin{array}{l}\text { Rehospitalized patients } \\
\qquad(n=68)\end{array}$ & $\begin{array}{l}\text { Non-rehospitalized patients } \\
\qquad(\mathrm{n}=463)\end{array}$ & p-value \\
\hline Illness duration (y) & $41.54 \pm 63.70$ & $44.84 \pm 77.25$ & NS \\
\hline Admission duration (d) & $25.69 \pm 11.93$ & $27.44 \pm 12.52$ & NS \\
\hline Number of previous depressive episodes & $1.56 \pm 2.67$ & $0.90 \pm 1.18$ & $0.048 *$ \\
\hline Number of previous psychiatric hospitalizations & $0.82 \pm 1.93$ & $0.29 \pm 0.83$ & $0.029 *$ \\
\hline Severity & & & NS \\
\hline Mild & $0(0.0)$ & $9(1.9)$ & \\
\hline Moderate & $11(16.2)$ & $74(16.0)$ & \\
\hline Severe & $57(83.8)$ & $380(82.1)$ & \\
\hline Presence of Pfs. & $4(5.9)$ & $41(8.9)$ & NS \\
\hline Presence of anxious distress & $9(13.2)$ & $107(23.1)$ & NS \\
\hline Family history of mood disorder & $17(25.0)$ & $63(13.6)$ & $0.014 \star$ \\
\hline \multicolumn{4}{|l|}{ Comorbid mental disorder } \\
\hline Substance use & $2(2.9)$ & $19(4.1)$ & NS \\
\hline Anxiety & $6(8.8)$ & $25(5.4)$ & NS \\
\hline Personality & $11(16.2)$ & $40(8.6)$ & $0.049 *$ \\
\hline
\end{tabular}

Values are presented as mean \pm standard deviation or number (\%).

Pfs., psychotic features; NS, not significant.

* $\mathrm{p}<0.05$ by independent $\mathrm{t}$-test or chi-square test or Fisher's exact test.

1-year rehospitalization group (1.56 \pm 2.67 times) and control group $(0.90 \pm 1.18$ times $)(p=0.048)$. There was significant difference in the number of previous psychiatric rehospitalizations between 1-year rehospitalization group $(0.82 \pm 1.93$ times) and control group $(0.29 \pm 0.83$ times) ( $\mathrm{p}=0.029)$. Family history of mood disorders showed statistically significant difference between the 1-year rehospitalization group (17 patients, $25.0 \%$ ) and control group (63 patients, $13.6 \%)(\mathrm{p}=0.014)$. Also, there was a significant difference in comorbidity of personality disorder between the 1-year rehospitalization group (11 patients, 16.2\%) and control group (40 patients, 8.6\%) $(\mathrm{p}=0.049)$. There was no significant difference between the two groups in duration of illness, duration of hos- 
pitalization, severity of depressive episode, presence of psychotic symptoms, presence of anxious distress, comorbidity of substance use disorders, and anxiety disorders (Table 2).

Multiple logistic regression analysis was performed on the following four clinical variables that were found to be significantly associated with 1-year rehospitalization in univariate analysis. The past number of psychiatric rehospitalizations was significantly associated with 1-year rehospitalization. For each increase in number of rehospitalizations, the adjusted odds ratio [OR] of 1-year rehospitalization increased by 1.319 (95\% confidence interval, 1.097-1.585; $\mathrm{p}=0.003)$. The number of depressive episodes in the past, family history of mood disorders, and comorbidity of personality disorders were not significantly associated with 1-year rehospitalization in multiple logistic regression (Table 3).

\section{One-year rehospitalization rate regarding the type of antidepressant}

Of all enrolled patients, the 1-year rehospitalization rate of the selective serotonin reuptake inhibitor (SSRI) group was $12.6 \%$ (36/286 patients), serotonin norepinephrine reuptake inhibitor (SNRI) group was $10.9 \%$ (15/138 patients), Mirtazapine group was $16.7 \%$ (3/18 patients), and tricyclic antidepressant, Bupropion etc. group was $15.7 \%$ (14/89 patients). There was no statisti- cally significant difference in the 1-year rehospitalization rate among the groups (Table 4).

\section{One-year rehospitalization rate regarding treatment method}

The 1-year rehospitalization rate of the antidepressant monotherapy group was $10.6 \%$ (28/264 patients), antidepressant combination group was $11.1 \%$ (7/63 patients), antidepressant and antipsychotic combination group was $18.8 \%$ (26/138 patients), antidepressant and mood stabilizer combination group was $7.1 \%$ (1/14 persons), antidepressants and antipsychotics and mood stabilizer combination group was $0.0 \%(0 / 14$ persons $)$, combination of two antidepressants and antipsychotics group was $16.7 \%$ (5/30 patients) and other treatment groups was $12.5 \%$ (1/8 patients). There were no statistically significant differences among the groups (Table 5).

\section{One-year rehospitalization rate depending on use of hypnotics}

Of the 531 patients, $61.4 \%$ (326/531 patients) used hypnotics. The 1-year rehospitalization rates were $11.7 \%$ (38/326 patients) and $14.6 \%$ (30/205 patients) in the group with hypnotics and without hypnotics, respectively; and there was no statistically significant difference (Table 6).

Table 3. Multiple logistic regression analysis for 1-year rehospitalization rate

\begin{tabular}{lccc}
\hline \multicolumn{1}{c}{ Variable } & Adjusted odds ratio & $95 \%$ confidence interval & $p$-value \\
\hline Number of previous psychiatric hospitalizations & 1.319 & $1.097-1.585$ & $0.003 \star$ \\
Family history of mood disorder & 1.804 & $0.954-3.411$ & 0.069 \\
Comorbid personality disorder & 1.975 & $0.951-4.100$ & 0.068 \\
\hline
\end{tabular}

$\star p<0.05$ by multiple logistic regression analysis.

Table 4. Comparison of 1-year rehospitalization rate among antidepressant groups

\begin{tabular}{lccc}
\hline \multicolumn{1}{c}{ Variable } & Rehospitalized patients & Non-rehospitalized patients & p-value \\
\hline SSRI $(n=286)$ & $36(12.6)$ & $250(87.4)$ & \\
SNRI $(n=138)$ & $15(10.9)$ & $123(89.1)$ & NS \\
Mirtazapine $(n=18)$ & $3(16.7)$ & $15(83.3)$ & $75(84.3)$ \\
Others $(n=89)$ & $14(15.7)$ & & \\
\hline
\end{tabular}

Values are presented as number (\%).

*p<0.05 by chi-square test.

SSRI, treatment with selective serotonin reuptake inhibitor; SNRI, treatment with serotonin norepinephrine reuptake inhibitor; Others, treatment with tricyclic antidepressant, bupropion, or vortioxetine; NS, not significant. 
Table 5. Comparison of 1-year rehospitalization rate among type of treatment

\begin{tabular}{|c|c|c|c|}
\hline Variable & Rehospitalized patients & Non-rehospitalized patients & p-value \\
\hline AD monotherapy $(n=264)$ & $28(10.6)$ & $236(89.4)$ & \multirow{7}{*}{ NS } \\
\hline$A D+A D(n=63)$ & $7(11.1)$ & $56(88.9)$ & \\
\hline$A D+A A P(n=138)$ & $26(18.8)$ & $112(81.2)$ & \\
\hline$A D+M S(n=14)$ & $1(7.1)$ & $13(92.9)$ & \\
\hline$A D+A A P+M S(n=14)$ & $0(0.0)$ & $14(100.0)$ & \\
\hline$A D+A D+A A P(n=30)$ & $5(16.7)$ & $25(83.3)$ & \\
\hline Others $(n=8)$ & $1(12.5)$ & 7 (87.5) & \\
\hline
\end{tabular}

Values are presented as number (\%).

*p<0.05 by Fisher's exact test.

$A D$, antidepressant; AAP, atypical antipsychotics; MS, mood stabilizer; NS, not significant.

Table 6. Comparison of 1-year rehospitalization rate between according to the use of hypnotics

\begin{tabular}{lccc}
\hline \multicolumn{1}{c}{ Variable } & Rehospitalized patients & Non-rehospitalized patients & p-value \\
\hline Hypnotics $(n=326)$ & $38(11.7)$ & $288(88.3)$ & NS \\
No hypnotics $(n=205)$ & $30(14.6)$ & $175(85.4)$ & \\
\hline
\end{tabular}

Values are presented as number (\%).

NS, not significant.

\section{Time to rehospitalization}

The mean period from discharge to rehospitalization was $141.85 \pm 118.68$ days and the median period was $109.00 \pm 118.68$ days in the 1-year rehospitalization group. Fourteen of sixty eight patients $(20.6 \%)$ of the 1-year rehospitalization group were rehospitalized within 14 days after discharge, and 35 of 68 patients (51.5\%) were rehospitalized within 120 days (Fig. 1).

\section{DISCUSSION}

This study showed that the higher the number of previous psychiatric hospitalizations is, the higher the 1-year rehospitalization rate would be. The number of previous depressive episodes, family history of mood disorders, and comorbidity of personality disorder showed significant association with 1-year rehospitalization in univariate analysis; however, they showed no significant association in multivariate analysis. There was no significant correlation between 1-year rehospitalization depending on the type of antidepressant, treatment method, and the use of hypnotics. The total 1-year rehospitalization rate was $12.8 \%$, of which $20.6 \%$ were reahospitalized within 2 weeks after discharge. The median time to rehospital-

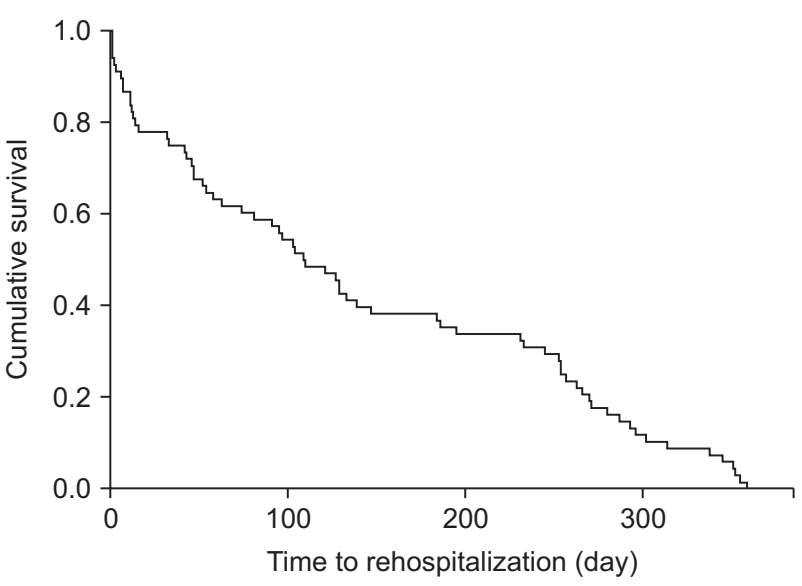

Fig. 1. Kaplan-Meier curve showing time to rehospitalization after discharge for 1-year rehospitalized patients.

ization was $109.00 \pm 118.68$ days.

Our results are consistent with the previous studies. This study again confirmed that the number of previous psychiatric hospitalizations is an important factor in predicting rehospitalization. This implies that patients who frequently visit psychiatric services have complex and repetitive problems that are difficult for improvement, and that this may make individuals vulnerable to crisis and lead to hospitalization [18].

The fact that the comorbidity of personality disorder 
showed a significant correlation with 1-year rehospitalization rate in the univariate analysis was not consistent with the results of some previous studies. Moreover, the result that family history of mood disorders showed significant correlation with the 1-year rehospitalization rate is new. In multiple logistic regression analysis, family history of mood disorders and comorbidity of personality disorders had an OR of $1.804(p=0.069)$ and an OR of $1.975(\mathrm{p}=0.068)$ for 1-year rehospitalization rate, respectively. Although not statistically significant, it was confirmed that these two factors had a trend towards association with 1-year rehospitalization. Therefore, it is possible that there may be a significant association in the multivariate analysis with a larger number of cases in future studies.

The mechanisms how family history of mood disorders affect the recurrence of depression are diverse [3]. Repeated parental depression during child raising period provides environmental factors such as a broken family environment [3]. In addition, a twin study revealed the genetic effects of depression and recurrent depression [21,22]. Family history of mood disorder can increase the rehospitalization rate by increasing the recurrence rate of depression. However, there may be an increased accessibility to psychiatric treatment due to the presence of a family member who has been treated for depression previously. Considering that satisfaction or prejudice on experience of psychiatric hospitalization may affect the decision of rehospitalization [23,24], it is thought that rehospitalization can be more easily determined since prejudice against psychiatric hospitalization is less than that of the general population. In addition, considering that family history of mood disorders is highly likely to create a relatively unstable environment [3], this may be a factor that can increase rehospitalization rate. Also, the patients may not be able to respond flexibly to stressful situations because they do not adequately learn adaptive behaviors growing up in an unstable parenting environment [23]. About 20\% of 1-year rehospitalization group was rehospitalized within two weeks of discharge and there was no significant difference in rehospitalization rates depending on antidepressant types and treatment methods. Thus, it can be presumed that the patient's coping skills to stress may be largely responsive for determining rehospitalization rather than therapeutic factors. Although previous studies showed that family history of depression was associated with recurrence of depression [24], there has been no result that it is associated with rehospitalization. The results of this study suggest that family history of mood disorders is a possible predictor of not only the recurrence of depression but also the predictor of rehospitalization; thus, further studies are needed.

There are controversial results on whether the comorbidity of personality disorder is a risk factor for recurrence of depression $[25,26]$. Moreover, previous studies claim that comorbidity of personality disorder is a risk factor for rehospitalization [8,12-14]. However, a prior study conducted in this institute did not show a significant correlation between personality disorder and rehospitalization [16]. It is likely for patients with personality disorder to show maladaptive behavior in stressful environments; therefore, it can be expected that recurrence of depression and rehospitalization will be higher than general population if the stressful environment is not relieved even after the patient is discharged. This study showed that personality disorder is a risk factor for rehospitalization in cross-sectional analysis. However, personality disorder showed no significant correlation with rehospitalization in multivariate analysis due to slight difference in p-value. Considering that there was no significant correlation on cross-analysis in a previous study in this institute [16], a significant correlation could be found with a larger number of cases and extension of included institutes. On the other hand, the proportion of personality disorders in patients with major depressive disorder was $44.0 \%$ according to foreign studies [27], but the rate of personality disorders among the patients in this study was remarkably low at $9.6 \%$. The reason for this is that diagnosis of personality disorder is often made from a long-term perspective. This may be due to that the diagnosis of personality in this study was based on the diagnosis at the time of standard hospitalization, excluding patients diagnosed with personality disorder through outpatient clinic after discharge. In addition, the tendency of clinicians to be more cautious in diagnosing personality disorder may partly explain its low rate of diagnosis. Therefore, if the data is collected and analyzed for a longer period, the results would be different from this study.

There was no significant difference among SSRI, SNRI, Mirtazapine and other drugs in the rehospitalization rate according to the type of antidepressant. This is consistent with the previous study conducted at this institute [16]. It is also consistent with previous studies which showed that the use of antidepressants lowered 
the recurrence of depression compared to placebo, but there was no difference in effectiveness among different types of antidepressant [28-30]. Therefore, the type of antidepressant will not have a significant difference in the degree of improvement of depressive symptoms or the influence on the decision to rehospitalization.

Comparison of readmission rates according to various treatments, including antidepressant alone, antidepressant and antipsychotic combined therapy, antidepressant and mood stabilizer combined therapy showed no significant difference in 1-year rehospitalization rates among each group. If the patient does not respond to the treatment or has partial responses only, the next step of treatment such as combined therapy of antidepressants or combined therapy with other drugs is recommended [31,32]. A previous study showed that antidepressant combination therapy was used in $24.3 \%$ to $26.0 \%$ and combination of other drugs was prescribed in $20.6 \%$ [33]. Some studies have demonstrated that antidepressant combination therapy shows higher remission rate compared to monotherapy [34], while others argue that there is no significant difference between combination therapy and monotherapy [35]. Moreover, a previous study argued that combination of antipsychotics increases the remission rate of depression [36], whereas a RCT study showed that the combination of fluoxetine and quetiapine did not significantly improve the symptoms of depression compared to fluoxetine alone [37]. The results of this study should be interpreted with caution in that antidepressants or other drugs are combined in cases resistant to treatment or of high severity $[31,32]$. The result that there is no significant difference in 1-year rehospitalization rate according to treatment methods can be interpreted as that the rehospitalization rate according to the severity of symptoms or the treatment response is a factor that can be controlled through treatment method. Therefore, the influence of the clinical variables is crucial in making the decision of rehospitalization than the type of treatment method.

On the other hand, although not statistically significant, it is noteworthy that only one patient was rehospitalized in the group of 28 patients who used mood stabilizers. According to a domestic study, when antidepressants were combined with other types of drugs, the most combined drugs were antipsychotics $(54.6 \%)$ followed by lithium (8.1\%), and anticonvulsants (7.4\%) [33]. In other words, combination therapy of antidepressants or with antipsychotics is more commonly used for treatment-resistant depression. However, the rehospitalization rates in this study were $18.8 \%$ and $16.7 \%$ in combination of antipsychotics and combination of other antidepressants and antipsychotics, respectively. These were rather higher compared to the total, although not statistically significant. The rehospitalization rate was $7.1 \%$ and $0.0 \%$ in antidepressant and mood stabilizer combination therapy and antidepressant, antipsychotic and mood stabilizer combination therapy, respectively. The higher rehospitalization rate in the combination treatment group with antipsychotics may be due to higher consideration of antipsychotics when the clinician determines that the patient clinical factors show tendency for rehospitalization or poor response to medication. The reason for decrease in rehospitalization rate, when mood stabilizer is combined, is expected to be largely affected by the patient's situational factors, maladaptive coping, impulsiveness, etc. as discussed earlier [3,23]. In such patients, mood stabilizers may be helpful in lowering rehospitalization rate. Meanwhile, a large-scale cohort study reported that lithium monotherapy was associated with the lowest rehospitalization rate in unipolar depressive disorder [38]. The results of this study also suggest that use of mood stabilizers in depressed patients may reduce recurrence of depression and rehospitalization.

Sleep disturbance is known to be a factor inducing depression [39], but there has been a lack of studies on its association with recurrence of depression. One study argued that sleep disturbance is an independent predictor for recurrence of depression [40]. In this study, there was no significant correlation between the use of hypnotics and rehospitalization. This may be due to the methodological differences between studies since Cho et al. [40] selected elderly patients aged 60 or above as study cases.

Of the 1-year rehospitalization group, $20.6 \%$ was rehospitalized within the first two weeks after discharge, and $51.5 \%$ was rehospitalized within 120 days. This implies that the decision on rehospitalization is often made early after discharge. As described above, this suggests that family conflicts, conflicts in relationships, stress, coping mechanisms, and impulsiveness $[3,23]$ have great influence on making decisions on rehospitalization, and also suggests that appropriate intervention of clinicians in these parts will be needed to prevent rehospitalization.

The overall 1 -year rehospitalization rate was $12.8 \%$. This is lower than that of previous studies, which showed $48 \%$ in a 5 -year rehospitalization rate survey of depressed patients [41] and $26.8 \%$ in a 2-year rehospital- 
ization rate survey [42]. However, this should be interpreted with caution considering that this study was only for patients who were followed up for one year, which is shorter compared to other studies. This is also because the study excluded patients who were lost during followup and were admitted to other institutions. Given this, the actual rehospitalization rate is expected to be higher than $12.8 \%$. These high rehospitalization rates highlight the importance of identifying factors affecting rehospitalization rates and making appropriate interventions.

The limitations of this study are as follows. First, the study was conducted only on patients who had been followed up in the hospital for one year. Thus, the patients who stopped treatment during follow-up or who visited other hospitals were not included. This may have caused a selection bias. Second, it was not possible to confirm the patient compliance to medication. During the outpatient follow-up, the clinician could not directly check the patient's medication. In addition, it is not possible to confirm the medication compliance through blood concentration measurement in clinical situations except for some mood stabilizers. Therefore, the analysis was conducted under the assumption that the patients faithfully took the medication according to prescription. Also, there is a possibility that rehospitalization due to the random discontinuation of the medication could not be identified. Third, this is a single center study conducted at a university hospital in Korea. Therefore there is likely to be a bias in the patient population. Furthermore, university hospitals in Korea have several administrative considerations that draw neuropsychiatric patients back from long enough hospitalization. Such factors would have had an impact on patient rehospitalization rate, especially on short-term rehospitalization, too. For these reasons, results from this study may have a few limitations to apply it to generalized populations. Fourth, it was difficult to evaluate the degree of improvement of symptoms upon discharge due to the lack of tools to objectively assess the severity of symptoms such as clinical global impression (CGI) and hamilton depression rating scale (HAM-D). Thus, the difference in rehospitalization rate according to the degree of improvement of symptoms could not be obtained.

\section{CONCLUSION}

A previous study of this institute on in-patients with major depressive disorder for 2 years found that only the number of previous psychiatric hospitalizations was significantly associated with 1-year rehospitalization rate [16]. In this study, the number of cases was more than doubled from 238 to 531 compared to the previous study. More variables were found to be significant compared to the previous study in the cross-analysis. This suggests that new variables associated to rehospitalization rate may be discovered with larger number of cases in future studies. Therefore, studies with larger number of cases, longer follow-up periods, and systematic evaluation should be conducted to thoroughly identify the factors affecting rehospitalization.

\section{CONFLICTS OF INTEREST}

The authors have nothing to disclose.

\section{ORCID}

\author{
Ji-Min Yoo \\ https://orcid.org/0000-0001-6257-7516 \\ Sung-Min Kim \\ https://orcid.org/0000-0002-3082-4014 \\ Yoo-Hyun Um \\ https://orcid.org/0000-0002-3403-4140 \\ Tae-Won Kim \\ https://orcid.org/0000-0003-2689-202X \\ Ho-Jun Seo \\ https://orcid.org/0000-0003-1661-1394 \\ Seung-Chul Hong \\ https://orcid.org/0000-0003-0828-2906 \\ Jong-Hyun Jeong \\ https://orcid.org/0000-0003-3570-7607
}

\section{REFERENCES}

1. Collins PY, Patel V, Joestl SS, March D, Insel TR, Daar AS, et al. Grand challenges in global mental health. Nature 2011;475:27-30.

2. Whiteford HA, Degenhardt L, Rehm J, Baxter AJ, Ferrari AJ, Erskine HE, et al. Global burden of disease attributable to mental and substance use disorders: findings from the Global Burden of Disease Study 2010. Lancet 2013;382: 1575-86.

3. Burcusa SL, Iacono WG. Risk for recurrence in depression. 
Clin Psychol Rev 2007;27:959-85.

4. Post RM. Transduction of psychosocial stress into the neurobiology of recurrent affective disorder. Am J Psychiatry 1992;149:999-1010.

5. Kupfer DJ, Frank E, Wamhoff J. Mood disorders: Update on prevention of recurrence. In: Mundt C, Goldstein MJ, Hahlweg K, Fiedler P, eds. Interpersonal factors in the origin and course of affective disorders. Gaskell: Royal College of Psychiatrists; 1996. p. 289-302.

6. American Psychiatric Association. Diagnostic and statistical manual of mental disorders: DSM-IV-TR. 4th ed. Washington: American Psychiatric Association; 2000.

7. Labbate LA, Doyle ME. Recidivism in major depressive disorder. Psychother Psychosom 1997;66:145-9.

8. Lin $\mathrm{CH}$, Chen YS, Lin CH, Lin KS. Factors affecting time to rehospitalization for patients with major depressive disorder. Psychiatry Clin Neurosci 2007;61:249-54.

9. Bardach NS, Coker TR, Zima BT, Murphy JM, Knapp P, Richardson LP, et al. Common and costly hospitalizations for pediatric mental health disorders. Pediatrics 2014;133: 602-9.

10. Noyola N, Sorgi K, Alday CS, Reidler EB. Clinical judgment at work: predicting rehospitalization in an adolescent inpatient unit. Brown Univ Child Adol Behav Lett 2014;30:1-8.

11. Lin CH, Chen MC, Chou LS, Lin CH, Chen CC, Lane HY. Time to rehospitalization in patients with major depression vs. those with schizophrenia or bipolar I disorder in a public psychiatric hospital. Psychiatry Res 2010;180:74-9.

12. Lin $\mathrm{CH}$, Chen $\mathrm{CC}$, Wang SY, Lin SC, Chen MC, Lin CH. Factors affecting time to rehospitalization in Han Chinese patients with schizophrenic disorder in Taiwan. Kaohsiung J Med Sci 2008;24:408-14.

13. Lin CH, Lin KS, Lin CY, Chen MC, Lane HY. Time to rehospitalization in patients with major depressive disorder taking venlafaxine or fluoxetine. J Clin Psychiatry 2008; 69:54-9.

14. Lerer B, Shapira B, Bloch M, Hanin B, Trudart T, Alexander JR, et al. Possible precipitants of psychiatric hospitalization in patients with major depression: results from the Jerusalem Collaborative Depression Project. Depress Anxiety 1999;9:156-62.

15. Haywood TW, Kravitz HM, Grossman LS, Cavanaugh JL Jr, Davis JM, Lewis DA. Predicting the "revolving door" phenomenon among patients with schizophrenic, schizoaffective, and affective disorders. Am J Psychiatry 1995;152: 856-61.

16. Seo MS, Jeong JH, Seo HJ, Lim HK, Kim TW, Park MH, et al. Clinical characteristics of patients with major depressive disorder that affect one-year rehospitalization rate: a retrospective study in a university hospital. Korean J Psychopharmacol 2014;25:141-8.

17. American Psychiatric Association. Diagnostic and statistical manual of mental disorders: DSM-5 ${ }^{\mathrm{TM}}$. 5th ed. Washington, D.C.: American Psychiatric Publishing; 2013.
18. Bernardo AC, Forchuk C. Factors associated with readmission to a psychiatric facility. Psychiatr Serv 2001;52:11002.

19. Sullivan PF, Neale MC, Kendler KS. Genetic epidemiology of major depression: review and meta-analysis. Am J Psychiatry 2000;157:1552-62.

20. Kendler KS, Neale MC, Kessler RC, Heath AC, Eaves LJ. Familial influences on the clinical characteristics of major depression: a twin study. Acta Psychiatr Scand 1992;86: 371-8.

21. Byrne SL, Hooke GR, Page AC. Readmission: a useful indicator of the quality of inpatient psychiatric care. J Affect Disord 2010;126:206-13.

22. Gebhardt S, Wolak AM, Huber MT. Patient satisfaction and clinical parameters in psychiatric inpatients--the prevailing role of symptom severity and pharmacologic disturbances. Compr Psychiatry 2013;54:53-60.

23. Goodman SH, Gotlib IH. Risk for psychopathology in the children of depressed mothers: a developmental model for understanding mechanisms of transmission. Psychol Rev 1999;106:458-90.

24. Rice F, Harold G, Thapar A. The genetic aetiology of childhood depression: a review. J Child Psychol Psychiatry 2002;43:65-79.

25. Lewinsohn PM, Rohde P, Seeley JR, Klein DN, Gotlib IH. Natural course of adolescent major depressive disorder in a community sample: predictors of recurrence in young adults. Am J Psychiatry 2000;157:1584-91.

26. Fombonne E, Wostear G, Cooper V, Harrington R, Rutter M. The Maudsley long-term follow-up of child and adolescent depression. 1. Psychiatric outcomes in adulthood. Br J Psychiatry 2001;179:210-7.

27. Melartin TK, Rytsälä HJ, Leskelä US, Lestelä-Mielonen PS, Sokero TP, Isometsä ET. Current comorbidity of psychiatric disorders among DSM-IV major depressive disorder patients in psychiatric care in the Vantaa Depression Study. J Clin Psychiatry 2002;63:126-34.

28. Borges S, Chen YF, Laughren TP, Temple R, Patel HD, David PA, et al. Review of maintenance trials for major depressive disorder: a 25-year perspective from the US Food and Drug Administration. J Clin Psychiatry 2014;75:20514.

29. Hansen R, Gaynes B, Thieda P, Gartlehner G, DeveaughGeiss A, Krebs E, et al. Meta-analysis of major depressive disorder relapse and recurrence with second-generation antidepressants. Psychiatr Serv 2008;59:1121-30.

30. Geddes JR, Carney SM, Davies C, Furukawa TA, Kupfer DJ, Frank E, et al. Relapse prevention with antidepressant drug treatment in depressive disorders: a systematic review. Lancet 2003;361:653-61.

31. Bauer M, Bschor T, Pfennig A, Whybrow PC, Angst J, Versiani M, et al. World Federation of Societies of Biological Psychiatry (WFSBP) guidelines for biological treatment of unipolar depressive disorders in primary care. World J Biol Psychiatry 2007;8:67-104. 
32. Bauer M, Whybrow PC, Angst J, Versiani M, Möller HJ. World Federation of Societies of Biological Psychiatry (WFSBP) guidelines for biological treatment of unipolar depressive disorders, part 1: acute and continuation treatment of major depressive disorder. World J Biol Psychiatry 2002;3:5-43.

33. Bae KY, Kim SW, Kim JM, Shin IS, Yoon JS, Jung SW, et al. Antidepressant prescribing patterns in Korea: results from the clinical research center for depression study. Psychiatry Investig 2011;8:234-44.

34. Blier P, Ward HE, Tremblay P, Laberge L, Hébert C, Bergeron R. Combination of antidepressant medications from treatment initiation for major depressive disorder: a double-blind randomized study. Am J Psychiatry 2010; 167:281-8.

35. Bares M, Novak T, Kopecek M, Stopkova P, Cermak J, Kozeny J, et al. Antidepressant monotherapy compared with combinations of antidepressants in the treatment of resistant depressive patients: a randomized, open-label study. Int J Psychiatry Clin Pract 2013;17:35-43.

36. Nelson JC, Papakostas GI. Atypical antipsychotic augmentation in major depressive disorder: a meta-analysis of placebo-controlled randomized trials. Am J Psychiatry 2009;166:980-91.

37. Garakani A, Martinez JM, Marcus S, Weaver J, Rickels K,
Fava M, et al. A randomized, double-blind, and placebocontrolled trial of quetiapine augmentation of fluoxetine in major depressive disorder. Int Clin Psychopharmacol 2008;23:269-75.

38. Tiihonen J, Tanskanen A, Hoti F, Vattulainen P, Taipale H, Mehtälä J, et al. Pharmacological treatments and risk of readmission to hospital for unipolar depression in Finland: a nationwide cohort study. Lancet Psychiatry 2017;4:547-53.

39. Ford DE, Kamerow DB. Epidemiologic study of sleep disturbances and psychiatric disorders. An opportunity for prevention? JAMA 1989;262:1479-84.

40. Cho HJ, Lavretsky H, Olmstead R, Levin MJ, Oxman MN, Irwin MR. Sleep disturbance and depression recurrence in community-dwelling older adults: a prospective study. Am J Psychiatry 2008;165:1543-50.

41. Daniels BA, Kirkby KC, Hay DA, Mowry BJ, Jones IH. Predictability of rehospitalisation over 5 years for schizophrenia, bipolar disorder and depression. Aust N Z J Psychiatry 1998;32:281-6.

42. Cearns M, Opel N, Clark S, Kaehler C, Thalamuthu A, Heindel W, et al. Predicting rehospitalization within 2 years of initial patient admission for a major depressive episode: a multimodal machine learning approach. Transl Psychiatry 2019;9:285. 